\title{
Technological advances to enhance recovery after cardiac surgery
}

\author{
Kevin W. Lobdell ${ }^{1}$, Jehangir J. Appoo ${ }^{2}$, Geoffrey A. Rose ${ }^{1}$, Brian Ferguson ${ }^{3}$, Subhasis Chatterjee ${ }^{4,5,6}$ \\ ${ }^{1}$ Sanger Heart \& Vascular Institute, Atrium Health, Charlotte, NC, USA; ${ }^{2}$ Libin Cardiovascular Institute, University of Calgary, Calgary, ALB, \\ Canada; ${ }^{3}$ Arena Labs, Westlake, OH, USA; ${ }^{4}$ Divisions of General and Cardiothoracic Surgery, Michael E. DeBakey Department of Surgery, Baylor \\ College of Medicine, Houston, TX, USA; ${ }^{5}$ Department of Cardiovascular Surgery, Texas Heart Institute, Houston, TX, USA; ${ }^{6} \mathrm{CHI}$ St Luke's Health \\ - Baylor St Luke's Medical Center; Houston, TX, USA \\ Contributions: (I) Conception and design: All authors; (II) Administrative support: None; (III) Provision of study materials or patients: None; (IV) \\ Collection and assembly of data: None; (V) Data analysis and interpretation: None; (VI) Manuscript writing: All authors; (VII) Final approval of \\ manuscript: All authors. \\ Correspondence to: Kevin W. Lobdell, MD. Atrium Health, PO Box 32861, Charlotte NC 28232, USA. Email: kevin.lobdell@atriumhealth.org.
}

\begin{abstract}
Surgery, and especially cardiac surgery, is common, costly, and entails considerable risk. Significant progress has been made in recent years to improve quality, promote patient safety, and increase value and cost-effectiveness in surgical care. Enhanced Recovery After Surgery (ERAS) initiatives are increasing in popularity, improving outcomes, and enriching patient satisfaction. First developed for abdominal surgical cases, ERAS has increasingly established itself across all surgical subspecialities, including cardiac surgery. ERAS focuses on evidence-based initiatives in the preoperative, intraoperative, and postoperative phases of care to promote patient well-being and efficient care. The deliberate, judicious incorporation of technology into surgery and the periprocedural home has tremendous, revolutionary potential in all phases of care and is consistent with ERAS principles. This technology can be harnessed by physicians and the care provider team, the healthcare system, and perhaps most importantly, by patients themselves to lead to a higher level of engagement. We will explore technology's transformational capability by concentrating on cardiac surgery because of its prevalence, costs, risks, and contribution to the healthcare system's bottom line. In addition, the role that ERAS combined with technology can play in a constructive manner will be important. We discuss the disruptive effect that the COVID-19 pandemic offers to accelerate these developments. While the human cost of the pandemic has been staggering, in the post-COVID world, the lessons learned can be vital. Finally, we seek to show that the opportunities technology provides are closely related to what both patients and the physician and provider teams want. As technology inevitably becomes more integrated into healthcare, the ability to harness technology to maximize patient outcomes and well-being while promoting more efficient healthcare delivery will be critical.
\end{abstract}

Keywords: Enhanced recovery; cardiac surgery; technology

Received: 07 August 2020; Accepted: 15 January 2021; Published: 25 September 2021.

doi: $10.21037 /$ jhmhp-20-114

View this article at: http://dx.doi.org/10.21037/jhmhp-20-114

\section{Introduction}

Health care is expensive. In 2017, the global burden of disease (GBD) was estimated to be $\$ 7.8$ trillion (in US dollars), or about $10 \%$ of the total global gross domestic product, which translates into approximately $\$ 1,080$ per capita for the world's population. In the United States, comparable numbers for health care costs are $19 \%$ of
US gross national product and $\$ 10,586$ per capita $(1,2)$. Moreover, this share of the GNP will continue to rise in the foreseeable future for several reasons, including the aging of the population and the advent of complex diagnostic and therapeutic advances. Indeed, in an International Business Machines (IBM) poll in 2012 of 480 economists, health care was determined to be the most inefficient system in the global economy, with waste estimated to be $\$ 2.5$ to 4 trillion 
annually (3). This healthcare inefficiency in the United States is complex and has been characterized by three types of waste: administrative waste at the national level (Medicare, private insurance), the level of which far exceeds that in comparable European and North American countries; significant operational waste (inefficient and unnecessary use of resources at the healthcare system/hospital level); and clinical waste (services that provide marginal or no health benefit at the individual patient level) (4). Given that productivity in health care lags behind that in other industries, such as information technology (IT), finance, insurance, real estate, and retail (5), a tremendous number of opportunities exist for improving healthcare, an industry with ever-diminishing profit margins in many of its sectors.

When the focus is narrowed to the global burden of surgery (GBS), estimates suggest that $11 \%$ to $28 \%$ of the GBD is attributable to the GBS. The associated worldwide surgical procedural volume is estimated to be 234 million operations annually, with an overall surgical mortality of approximately $0.4 \%$ and morbidity estimates ranging from $3 \%$ to $17 \%$ (6-14). Surgical complications correlate with additional costs and diminished life expectancy. Results of the American College of Surgeons' National Surgical Quality Improvement Program analysis indicated that any one of 22 distinct complications that developed in the first 30 days postoperatively reduced patients' median life expectancy by an average of 69\% (range 44-77\%) (15). Thus, the imperative to reduce the incidence of perioperative complications is clear.

When the focus is even further narrowed to acquired heart disease, we can see the widespread prevalence of its impact. Acquired heart disease affects 30.3 million adults (12.1\% of the US adult population) (16), and the Society of Thoracic Surgeons' Adult Cardiac Database indicates that approximately 295,000 cardiac surgical operations are performed annually, with a mortality rate ranging from 1 to $10 \%$, depending on the procedure (17). The incidence of complications associated with cardiac surgery ranges from $33 \%$ to $54 \%$ for all complications and from $11 \%$ to $17 \%$ for major complications (which include stroke, reoperation, prolonged ventilation, deep sternal wound infection, and acute renal failure; minor complications include atrial fibrillation (AF), pleural effusion, pneumonia, and deep venous thrombosis). These complications reduce life expectancy, increase patient and family dissatisfaction, have adverse implications for hospital-based quality metrics, and increase health care costs (18).
Capital expenditures on health IT continue to increase, to a projected $\$ 6.4$ billion in 2021 , a nearly $7 \%$ increase over the last five years (19). Although the optimal threshold remains unknown, this proportion will inevitably continue to increase steadily. That said, it is noteworthy that digital health venture capital increased nearly 10 -fold from 2010 to 2017; more than $\$ 40$ billion was invested in digital health in the 2010s, reflecting the robust promise in this arena (20).

The burgeoning field of digital health care (21) includes telemedicine, the Internet of Medical Things (IoMT), remote patient monitoring devices, patient engagement and empowerment tools, software as medical device, advanced analytics, artificial intelligence (AI), cloud-based storage platforms, cybersecurity, wireless medical devices, mobile medical applications for smart phones, and novel digital devices $(22,23)$. Indeed, this field has advanced so rapidly that technologies that were inconceivable to healthcare practitioners a decade ago will become routinely used in the next $5-10$ years.

\section{Enhanced recovery}

To confront the healthcare challenges facing the country, the Institute for Healthcare Improvement (IHI) has developed the "Quadruple Aim" of population health: better outcomes, improved patient experience, improved clinician experience, and reduced costs to improve the value of health care (24). Achieving these goals is central to the Enhanced Recovery After Surgery (ERAS) movement. This initiative has worked toward improving the quality and value of surgical care by combining multimodal strategies that mitigate the stress response to reduce postoperative pain without opioids, overcome postoperative ileus, and reduce intravascular volume shifts while preserving and enhancing physiologic reserve (25-28). The invasiveness and duration of cardiac surgery and cardiopulmonary bypass amplify the routine physiologic stressors of surgery by causing more profound metabolic, inflammatory, and immunologic derangements $(29,30)$. The ERAS efforts focus on the critical members of the perioperative care team: surgeon, anesthesiologist, intensivist, nurse, perfusionist, physical therapist, pharmacist, and nutritionist, among others. Furthermore, these perioperative care efforts highlight the British cycling coach Sir David Brailsford's concept of the "aggregation of marginal gains" whereby small, incremental gains across a broad platform of processes can cumulatively achieve meaningful benefits and improved outcomes (31).

Ultimately, the benefit of any technological advance 
is determined by whether it serves the needs of patients and their physicians and care teams. An insightful survey from the James Lind Alliance Priority Setting Partnership in adult heart surgery (32) addresses this question. This survey of 629 heart surgery patients, caregivers, and health care professionals aimed to identify their biggest priorities with respect to cardiac surgery. While patients and providers had slightly different highest priorities, the most common questions focused on basic information (improving outcomes in patients with comorbidities, when heart valve intervention should occur in asymptomatic patients, minimally invasive vs. open heart surgery), quality of life (expected course after heart surgery, frailty and heart surgery, the value of prehabilitation), and the risks and management of postoperative complications (minimizing damage to other organ system and reducing postoperative AF or wound infections). This information about patients' priorities helps clinicians recognize that they and their patients do not necessarily have the same focus when it comes to surgery. The ultimate embrace of the technological advances will rest on how well these priorities are addressed for all involved; indeed, patient empowerment and shared clinical decision-making are increasingly recognized as the major determinants of value (33).

In addition to meeting patient and provider expectations, technology that transforms health care will also need to meet the Quadruple Aim, bend the cost curve down, and promote real growth in productivity to benefit the healthcare system. Specifically, technology can aggregate and integrate volumes of clinical, care process, and financial data that can be rapidly analyzed to provide insight and improve care. Care variation, responsible for many disparate outcomes in health care, can be reduced, and outcomes can be reliably improved. Technology also bolsters risk assessment and decision support. Similarly, technology can reduce friction between employees by enhancing interoperability, workflow, and ease of use. The opportunity to identify premium talent can be leveraged with technology by evaluating adherence to standards of care and recognizing superior outcomes.

\section{Solutions and technologies}

The world has been rapidly transformed by computing and the internet into a less centralized network of people and technology $(34,35)$. These developments have been outlined by Peter Diamandis and Steven Kotler and classified into the "Six Ds" of exponential technologies:
Digital information tools that Deceptively increase in scope and utilization to Disrupt, Demonetize, Dematerialize, and Democratize information while accelerating the ongoing transformation (36). All of these principles conform to the ERAS goals of empowering the patient and healthcare team by creating a more streamlined, evidence-based care pathway that is followed both in the hospital immediately after surgery and at home during recovery.

\section{Data as a platform}

Data as a platform (DAAP), which fuses the technology ecosystem and satisfies the specific needs of different users, is foundational to enhancing and transforming surgical care (37). The growth of health data is staggering, with 153 exabytes (i.e., one quintillion bytes) produced in 2013 and as many as 2,314 exabytes forecasted for 2020 (48\% annual increase) (38). Strategic imperatives for DAAP include scalability, rapid onboarding of novel data sources, and support of all types of data and analytics. The potential benefits will include improved personalization, access, prediction, health, and quality and cost of care $(39,40)$. However, issues regarding governance, security, and privacy are important and will require thoughtful consideration from all stakeholders in the health care enterprise.

\section{Wearables and the Internet of Medical Things}

Approximately $80 \%$ of patients have smartphones, and $90 \%$ have some type of mobile phone. Additionally, $17 \%$ to $29 \%$ of patients check their smart device 50 or more times a day. The average person uses their phone 2.5 hours daily, and more than one-third of people look at their smartphone within 5 minutes of waking up (41-43). Wearables, such as smartwatches and fitness bands, are used by $5 \%$ to $11 \%$ of the world's adult population (42). The complementary and unique digital connection to patients provides an opportunity to improve quality and value as components of the IoMT, where-this year-an estimated 28 billion discrete data elements will be connected (44). This incredible penetration of technology provides a rich infrastructure that can be easily incorporated into the health care ecosystem, where the prospects of ERAS can be transformational. By providing patients with wearable technology, a unique level of patient engagement can be harnessed for earlier identification of potential problems and deviations from the expected postoperative course.

The average age of adult cardiac surgery patients is 
greater than 60 years. In this patient population, attention is required to address technical challenges with setup and use due to impaired "mobility, vision, memory, and hearing, plus, all too frequently, social isolation, loneliness, and depression" (45). It is important to remember that, for some older individuals, there is a valuable aspect of social interaction with the health care system that technologic solutions will supplant. The process of engaging patients via remote monitoring is important and involves building rapport, sharing information, and providing guidance (46). Our patient rate of compliance in this population is favorable $(>90 \%)$ and exceeds the rates documented by others $(47,48)$. As Krishnaswami and colleagues (49) highlight, the key to gerotechnology as it addresses cardiovascular care is to improve patient-centered care, lower treatment-related risk, improve quality of life, and alleviate symptoms. This involves identifying the goals of care, assessing the barriers to the digital use of health, optimizing the match between patient and technology, providing adequate support to the participant and caregiver, and continually reassessing the impact of these technologies and optimizing the process further. Improving the engagement of older patients can have positive effects and may reduce readmissions if potential complications are recognized early on, with clear financial benefits to the healthcare system.

One opportunity that wearable technology provides is in optimizing care for $\mathrm{AF}$. $\mathrm{AF}$ is a common cardiac arrythmia and is associated with increased risk of morbidity from stroke, mortality, and healthcare expenditures. Its prevalence is estimated at almost $1 \%$ of the general population and $10 \%$ of people aged 65 years or older, with a sizable portion of cases (13\%) being undiagnosed (50). The Stanford University Apple Heart Study is the archetype for using wearable technology (Apple Watch) for pragmatic, large-scale studies of prevalent and vexing health care problems such as AF (51-53). Of the 400,000 participants recruited, 2,161 (0.52\%) received an irregular pulse notification on their smart phone. One-third of these participants were found to have AF, which allowed early diagnosis and management of this condition.

\section{Intelligent computing}

AI was pioneered by Alan Turing (54), as well as by John McCarthy and his colleagues at Dartmouth College (55). AI can be defined as "the branch of computer science dealing with the simulation of intelligent behavior in computers" (56) and includes sensing, engaging, reasoning or decision making, and learning (57). AI maintains great promise in prescriptive (what we should do) health care computing efforts and will complement descriptive (what happened) and proscriptive (what could happen) computing.

The process of producing AI algorithms is complex, requiring experts, computing power, and large volumes of robust data structured in an organized fashion. AI algorithms can be static (unchanged over time) or dynamic, whereby data and outcomes create a virtuous cycle by continuing to inform and update the algorithms $(58,59)$. This dynamic process and its potential are fueling rapid growth in health care AI; future investment in this area is projected to be $\$ 6.6$ billion in 2021 and $\$ 36$ billion by 2025 (with a compound annual growth rate of $40 \%$ to $45 \%$ ) $(60,61)$. According to Accenture, "when combined, key clinical health AI applications can potentially create $\$ 150$ billion in annual savings for the US health care economy by 2026" (62). The US Food and Drug Administration (FDA) has provided guidance on $\mathrm{AI}$ algorithm development but, to date, does not have a standardized validation process $(63,64)$.

Similar to linear regression risk models, the quality of algorithms can be measured according to discrimination and calibration, as well as precision, recall, and accuracy (65). The risks of AI include, but are not limited to, bias and diminution of clinician decision making (66).

Various classifications are used to categorize and characterize AI. Familiar types of AI used in health care include machine learning, whereby computers learn, improve, make predictions, and process and analyze language (i.e., natural language processing) $(67,68)$. The use of $\mathrm{AI}$ in cardiac care includes risk modeling (preoperative and postoperative), imaging, and natural language processing for electronic medical records (69). The potential of AI to further develop ERAS concepts may help to refine future iterations of ERAS guidelines. Moreover, in the operational framework outlined by Bentley and colleagues (4), the concept of clinical waste and reducing services that provide little or no benefit to the patient can be reduced once meaningful data are harvested and analyzed, and care pathways and protocols can be developed and implemented.

\section{Complex modeling}

Complex modeling, in which computers simulate complex systems with a combination of mathematics and physics, has been used effectively in weather and aviation simulations and is now increasingly used in biologic systems (70). 
For example, complex modeling is being used to evaluate anatomic, physiologic, and pathophysiologic phenomena and shows great promise in predictably improving the care of cardiovascular patients (71). Valuable examples of this technology include characterizing relationships of ventricular volume, wall stress, and stroke volume associated with surgical ventricular reconstructive procedures or other intracardiac devices $(72,73)$.

\section{Virtual assistants}

Virtual assistants can help with routine tasks such as compliance with therapeutic regimens, engagement and behavior modification, and schedule management and reminders $(74,75)$. There is considerable optimism that virtual assistants, integrated with novel tools and evolving processes, can improve access to care, coordination of care, efficiency, engagement, and, ultimately, outcomes (75). The ability to harness virtual assistants for patient care can ensure that patients continue following the expected recovery course, consistent with ERAS goals.

\section{Additive manufacturing}

Additive manufacturing, also known as $3 \mathrm{D}$ printing (3DP), uses computer-aided design or a scanner for input and a printer that adds material layer by layer to create an object (76). Charles Hull created the first machine part with $3 \mathrm{DP}$ in 1983, and the process is now used to provide parts in aerospace and automobile industries with an "on demand" capability to increase efficiency (77). For health care, data acquisition in the $3 \mathrm{DP}$ process can be done by using computerized axial tomography, magnetic resonance, and echocardiography to facilitate rapid prototyping for product development, custom implants, anatomic models, and virtual surgical planning, among others (78). Customized transcatheter replacement valves and endovascular aortic stent grafts are notable examples of $3 \mathrm{DP}$ products used to treat cardiovascular disease (78).

\section{Simulation}

Augmented reality (AR) has been used to remotely match rare, experienced talent with uncommon problems in other fields, such as automobile repair (79). One can easily extrapolate and realize AR's potential in educating surgeons and performing technically challenging or high-risk surgical procedures (80-82). As we integrate advanced imaging and minimally invasive approaches, the potential usefulness of AR and virtual reality (VR) is advancing significantly and synergistically $(83,84)$. Over time, this can lead to the development of better simulation exercises to train the entire perioperative care team to anticipate and react various complications in the perioperative period (85). The concept of failure to rescue is an important determinant of variation in mortality after coronary artery bypass grafting (CABG) surgery (86). Namely, the difference among hospitals is not so much the difference in the incidence of major complications such as stroke, renal failure, or prolonged mechanical ventilation; rather, the difference is in how quickly complications are recognized and treated to mitigate their severity.

\section{Telebealth}

Telehealth provides patients with remote access to health care via real-time, audiovisual technology. The solutions can be particularly valuable for solving access problems that result from disparities, disabilities, long physical distance from health care centers, and a lack of expertise and specialized personnel, as well as from high-risk situations such as virulent infections and combat. Administrative and clinical data can accrue from telehealth solutions and provide the opportunity to exponentially increase the value of these efforts.

The electronic intensive care unit (eICU) has been in existence for more than 15 years and has shown promise for enhancing the quality and reducing the cost of ICU care while also providing flexibility for clinical teams and scalability to include small ICUs or multiple large ICUs (87-92). In addition to the audiovisual technology utilized in the eICU, large volumes of clinical data can be acquired and analyzed to assist with prioritization, workflow, and decision support (93-95). Similarly, "tele-rounding" has been used for many years to leverage expertise and also to address the challenges of COVID-19 to minimize patients' and clinicians' risk of exposure $(96,97)$. This clearly illustrates how technology could meet a specific need created by the COVID-19 pandemic. As social distancing requirements prevented the intensive care unit (ICU) multidisciplinary rounding process from being conducted in its normal fashion, virtual rounding became a necessity to reduce the likelihood of SARS-CoV-2 transmission among members of the healthcare team. These challenges were anticipated by ERAS thought leaders, who offered guidance to navigate cardiac surgery perioperative care in the COVID world (98). 
Although telemedicine will continue to become more prevalent, it is important to remember that in-person communication among patient, nurse, and physician still has a valuable reassuring and therapeutic role that technology platforms should strive to enhance and not eliminate.

\section{Cybersecurity}

The novel and large volumes of data that provide a rich opportunity to transform health care present a real and growing risk. Cybersecurity risks include the hacking of medical insurance information, office and hospital medical records, and devices, in addition to phishing and geolocation threats (3,99-102). Interestingly, approximately $25 \%$ of health care cybersecurity attackers are "insiders," which is an order of magnitude greater than that seen in financial services, manufacturing, and retail (3). It is estimated that 175 million records have been breached since 2010, with offices and hospitals being the most frequently targeted victims of cybercrime and insurance companies having lost the greatest volume of records (99). Twofactor authentication and other strategies to reduce the vulnerability of medical records are increasingly prevalent and effective; these measures will not only reduce the actual risk of hacking but also preserve the public's faith in the integrity of the system.

\section{Solutions and technologies by phase of care}

\section{Acute care}

\section{Preoperative care and prehabilitation}

The novel coronavirus (COVID-19) pandemic has accelerated the use of telemedicine and digital health across most subspecialties, including cardiovascular care. The exponential growth of this demand for increased technology requires a "network" solution (i.e., better technological solutions and processes to accelerate information flow, decision making, and the matching of demands with resources) (103). Atrium Health's Sanger Heart and Vascular Institute in Charlotte, North Carolina rapidly transitioned to approximately $95 \%$ virtual visits (>500/day) (104), and McKinsey \& Company data show that "consumer adoption has skyrocketed, from 11 percent of US consumers using telehealth in 2019 to 46 percent of consumers now [middle of 2020] using telehealth... and providers have rapidly scaled offerings and are seeing 50 to 175 times" (105). Furthermore, McKinsey \& Company asserts that approximately $\$ 250$ billion in care could be virtualized (105).

The four pillars of remote patient monitoring are (I) engagement via video visits, messaging, pathways, protocols, and patient reported outcomes (PROs); (II) a secure audiovisual interface; (III) biosensors that allow clinicians to acquire data in a way that replaces and supersedes the traditional physical exam; and (IV) data management and analytics that can apply AI, and specifically machine learning, algorithms to large amounts of data generated by sensors $(106,107)$. Each of these technologies will have variable roles and applications for different patient subsets, but the ERAS concepts can be tied into all aspects of remote patient monitoring.

Preoperative, quantified risk assessment should be routinely performed to help patients and clinicians make decisions and plans (and there is strong evidence that greater risk correlates with greater complications and costs) $(18,108,109)$. Technologies such as cardiopulmonary exercise testing and anaerobic threshold quantification (110-112), biomarkers (113-115), and frailty $(116,117)$ could be incorporated into routine risk assessment and guide modifiable risk-mitigation strategies. Evidence-based approaches that promote prehabilitation can contribute meaningfully to optimizing patients for surgery.

The aggregation of novel and large volumes of data fuels AI's capacity to improve the efficacy and speed of the modeling process for mortality and morbidity (118-120). This platform offers patients and referring clinicians the opportunity for genuine informed consent and realistic, individualized assessments of risk and recovery prospects before surgery. AI has been investigated in various types of testing and imaging. AI has been utilized in electrocardiography for dysrhythmia detection and in chest radiography, with promising results in accuracy and speed of interpretation (121-123). AI also exhibits promise in more advanced imaging such as echocardiography and MRI $(124,125)$.

Of the 25 machine learning algorithms that received FDA approval as of 2019, 13 of them were for medical imaging, mostly cardiovascular and breast imaging (126). Of the 12 non-imaging-related algorithms, three were for detecting AF. FDA approvals will continue to increase as AI algorithms proliferate across all areas of medicine and are validated in different contexts and clinical settings. Recent contributions in cardiovascular surgery are highlighted in a review by Kilic (59) indicating that the role for AI will only continue to increase in scope.

Novel remote monitoring tools in cardiovascular care are 
currently being used by a few centers in the management of congestive heart failure, dysrhythmia detection, and perioperative care $(127,128)$. Monitoring of vital signs with cloud-based data sharing is provided by a variety of companies, each with different niches (129-134). An important, emerging area is engagement tools and PROs that increase patients' involvement in their care. Mobile device applications, commonly used in nonmedical settings, are now used to guide patients through their cardiac surgery journey, measure their well-being, and decrease complications $(106,107)$. The next generation of ERAS cardiac guidelines will continue to define the appropriate implementation phase and roles for these technologies.

\section{Operating room}

Robotic surgery and telesurgery have the potential to help with surgical education, treating remote patients, risky environments, and ergonomics (135-137). The operational workflow, which allows a day's worth of operations to be completed efficiently, can also be monitored and improved (138). In the realm of the individual surgeon, surgical coaching with technology offers great promise to improve surgical skills and outcomes (139). This type of coaching is not natural to surgeons in practice, but just as major league baseball players have hitting coaches and watch videotapes of their performance, similar, periodic engagements of surgeons in practice may be an opportunity to enhance lifelong learning.

"Hyper-realistic" training modules created to simulate real-world stress and measure the stress response and regulation with VR (ARENAXR) (140) have the power to train surgical teams in pioneering ways that focus beyond technical skill acquisition to include human factors such as stress, decision-time, and 360-degree awareness.

As noted above, wearables for tracking activity, recovery, and sleep are becoming ubiquitous, easy to use, and affordable. By placing sensors on frontline medical teams to track stress and rest, medical leaders-for the first time in history-have the ability to create real-time dashboards on their health and performance and, more importantly, be sophisticated about understanding burnout (141). Most medical practitioners traditionally have been treated in a "one size fits all" manner; perhaps these dashboards will allow more individualization and personalization in several areas. This will become critical as the cardiovascular surgical workforce becomes more diverse. Moreover, healthcare organizations demonstrating concern for the well-being of their workforce will be seen, not simply as a bonus, but as a necessity for the next generation of healthcare workers.

Similar to commercial aircraft black boxes, the operating room can be outfitted for "real-time data capture and deep clinical analysis of operating room activity...and this information provides comprehensive, objective, and clinically relevant insights into the perioperative environment" (142). The potential benefits for quality and safety are manifold (143-145). Technology also exists to mitigate the risk of "never events" such as retained objects (146-148). An important consideration in all of these technologies is who owns the data: hospitals, the individual surgeon, the patient, the third-party payor? What happens if malpractice is alleged or hospital disciplinary actions are invoked and these recordings are used, not as an opportunity for improvement, but as a means for reprimand, censure, or litigation? These issues are not simple and will require thoughtful deliberation and the establishment of boundaries, respecting the privacy of not just the patient but also the healthcare team.

Traditional data sets can be augmented with additional data (such as the number of admissions, the complexity of patients as measured by acuity scores, high patient-to-nurse ratios, and the experience level of staff) to improve risk assessment and mitigation $(65,149)$.

\section{Post-acute care}

Continuity, connectivity, and coordination across the continuum are valuable for transforming health care and vital for higher-risk endeavors such as surgery (75). As the archetype for the advanced, cardiac, periprocedural home, Perfect Care remotely monitors cardiac patients with a combination of video visits; messaging that includes images; biometrics via fitness trackers, scales, and sphygmomanometry; and PROs (150). A precision, personalized approach can be tailored to include pulse oximetry, glucometry, and monitoring of anticoagulation (150-152). In the first nine months of Perfect Care at the Sanger Heart and Vascular Institute, the observed median postoperative length of stay was half a day less than the benchmark, and the readmission rate was approximately $60 \%$ of the benchmark (KWL, unpublished data, 01 July 2019-28 February 2020).

Virtual cardiac rehabilitation has improved compliance, reduced readmissions, and reduced associated costs, as well as producing a sustained reduction of cardiovascular risks (e.g., increased exercise capacity and dietary quality, with reductions in cholesterol levels) (153-155). Table 1 lists these 
Table 1 Valuable enhanced recovery technologies by designee and phase of care

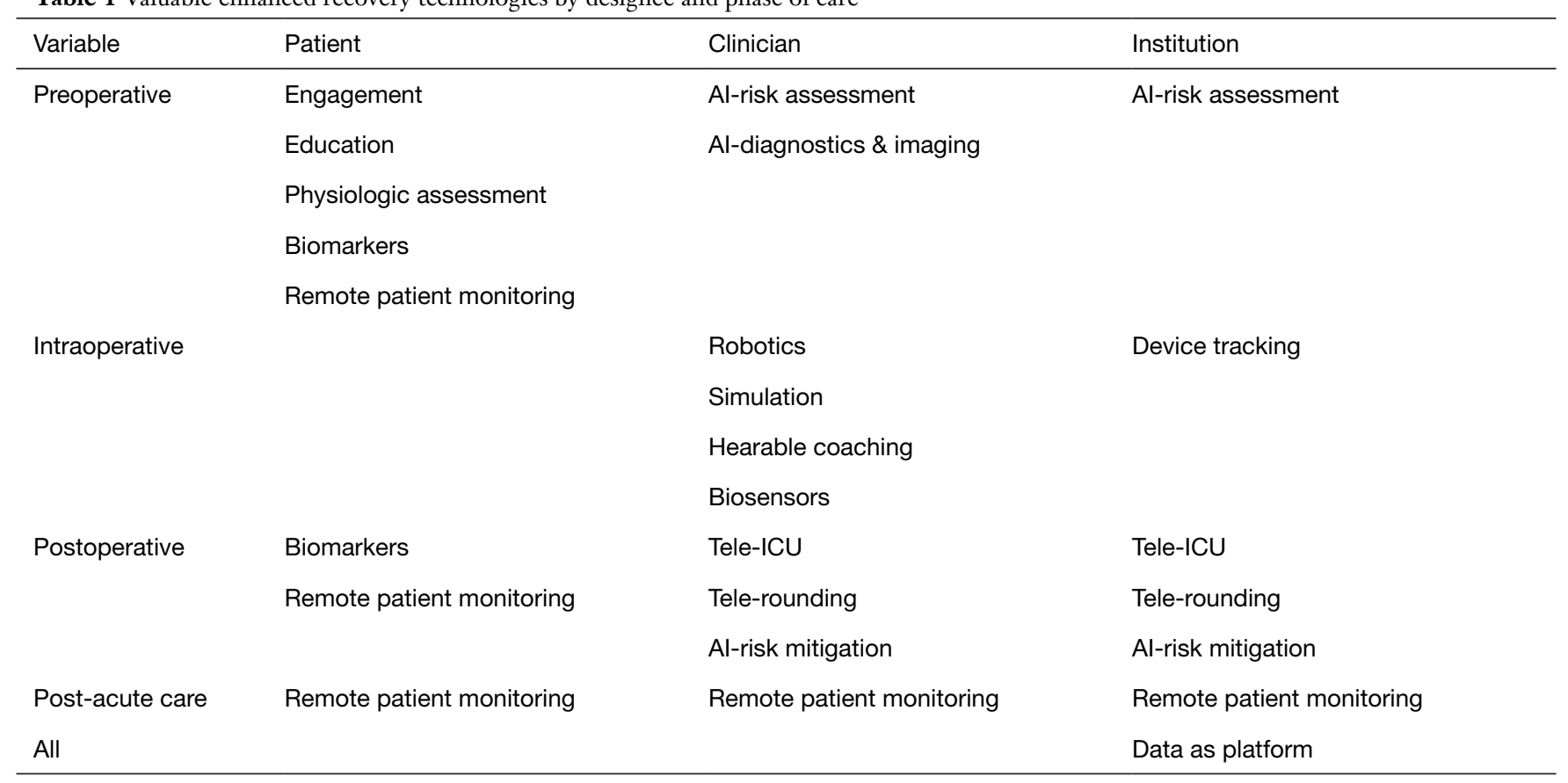

$\mathrm{Al}$, artificial intelligence; ICU, intensive care unit.

technologies and the phases of care that offer the most potential to enhance recovery.

\section{Summary and future}

A more adaptable, higher-quality, safer, and, ultimately, more valuable health care system requires improved efficiency and efficacy in matching demands with resources. Technologies to improve data management and analytics, digital and telehealth tools, simulation, enhanced cybersecurity, and others, combined with ERAS efforts, have tremendous potential to assist in realizing the IHI's Quadruple Aim. The COVID-19 pandemic may accelerate many of these processes to transform the health care landscape more rapidly than we could have imagined mere months ago.

The near future of enhanced recovery efforts will include aggregating the most valuable technologies, ascertaining interoperability, and seamless workflow, as well as engagement, learning, and optimization from both patient and clinician perspectives. It will be important to rigorously scrutinize the actual data and the outcomes of its use. Technological advances are not intrinsically valuable in and of themselves; ultimately, they must translate into actual benefits for patients, health care providers, and health care systems.

The future will also include advancement of knowledge about engagement, improved education and implementation, and mitigating the risk of clinician burnout. Technological advancements will be made in intelligent computing, novel biosensors, faster networks, and the incorporation of genomics, proteomics, and other biotechnologies, as well as quantum computing. The role of technology and enhanced recovery efforts will be a catalyst for optimizing patient outcomes after cardiac surgery.

\section{Acknowledgments}

The authors thank the Texas Heart Institute's Scientific Publications Department for providing editorial support and Katherine A. Lobdell for manuscript review.

Funding: None.

\section{Footnote}

Provenance and Peer Review: This article was commissioned by the Guest Editors (Naleef Fareed, Ann Scheck McAlearney, and Susan D Moffatt-Bruce) for the series "Innovations and Practices that Influence Patient-Centered Health Care Delivery" published in Fournal of Hospital 
Management and Health Policy. The article has undergone external peer review.

Peer Review File: Available at http://dx.doi.org/10.21037/ jhmhp-20-114

Conflicts of Interest: All authors have completed the ICMJE uniform disclosure form (available at http://dx.doi. org/10.21037/jhmhp-20-114). The series "Innovations and Practices that Influence Patient-Centered Health Care Delivery" was commissioned by the editorial office without any funding or sponsorship. Dr. KWL is an independent quality consultant for Medtronic Inc. and Abiomed and a recipient of a Duke Endowment Grant-Perfect Care. Dr. JJA is a consultant for Gore Medical \& Cryolife and the founder of AloTHealth.ca. The authors have no other conflicts of interest to declare.

Ethical Statement: The authors are accountable for all aspects of the work in ensuring that questions related to the accuracy or integrity of any part of the work are appropriately investigated and resolved.

Open Access Statement: This is an Open Access article distributed in accordance with the Creative Commons Attribution-NonCommercial-NoDerivs 4.0 International License (CC BY-NC-ND 4.0), which permits the noncommercial replication and distribution of the article with the strict proviso that no changes or edits are made and the original work is properly cited (including links to both the formal publication through the relevant DOI and the license). See: https://creativecommons.org/licenses/by-nc-nd/4.0/.

\section{References}

1. Organisation for Economic Cooperation and Development. Health at a Glance 2019: OECD Indicators. 2019. Available online: https://www.oecd-ilibrary. org/sites/876d99c3-en/index.html?itemId=/content/ component/876d99c3-en. Accessed July 82020.

2. World Health Organization. Global Spending on Health: A World in Transition. 2019. Available online: https:// www.who.int/health_financing/documents/healthexpenditure-report-2019.pdf. Accessed July 82020.

3. IBM. Do You Know Where Your Health System is Vulnerable? Available online: https://www.ibm.com/ industries/healthcare/resources/spot-cybersecuritythreats/. Accessed July 82020.
4. Bentley TG, Effros RM, Palar K, et al. Waste in the U.S. Health care system: a conceptual framework. Milbank Q 2008;86:629-59.

5. Sahni NR, Huckman RS, Chigurupati A, et al. The IT Transformation Health Care Needs. Harvard Business Review. 2017. https://hbr.org/2017/11/the-ittransformation-health-care-needs. Accessed July 82020.

6. Bickler S, Ozgediz D, Gosselin R, et al. Key concepts for estimating the burden of surgical conditions and the unmet need for surgical care. World J Surg 2010;34:374-80.

7. Haynes AB, Weiser TG, Berry WR, et al. A surgical safety checklist to reduce morbidity and mortality in a global population. N Engl J Med 2009;360:491-9.

8. Meara JG, Leather AJ, Hagander L, et al. Global Surgery 2030: Evidence and solutions for achieving health, welfare, and economic development. Surgery 2015;158:3-6.

9. Ozgediz D, Chu K, Ford N, et al. Surgery in global health delivery. Mt Sinai J Med 2011;78:327-41.

10. Ozgediz D, Jamison D, Cherian M, et al. The burden of surgical conditions and access to surgical care in lowand middle-income countries. Bull World Health Organ 2008;86:646-7.

11. Shrime MG, Bickler SW, Alkire BC, et al. Global burden of surgical disease: an estimation from the provider perspective. Lancet Glob Health 2015;3 Suppl 2:S8-9.

12. Shrime MG, Daniels KM, Meara JG. Half a billion surgical cases: Aligning surgical delivery with bestperforming health systems. Surgery 2015;158:27-32.

13. Tollefson TT, Larrabee WF, Jr. Global surgical initiatives to reduce the surgical burden of disease. JAMA 2012;307:667-8.

14. Weiser TG, Regenbogen SE, Thompson KD, et al. An estimation of the global volume of surgery: a modelling strategy based on available data. Lancet 2008;372:139-44.

15. Khuri SF, Henderson WG, DePalma RG, et al. Determinants of long-term survival after major surgery and the adverse effect of postoperative complications. Ann Surg 2005;242:326-41; discussion 41-3.

16. National Center for Health Statistics. Heart Disease. Centers for Disease Control and Prevention. 2017. Available online: http://www.cdc.gov/nchs/fastats/heartdisease.htm. Accessed July 82020.

17. Bowdish ME, D'Agostino RS, Thourani VH, et al. The Society of Thoracic Surgeons Adult Cardiac Surgery Database: 2020 Update on Outcomes and Research. Ann Thorac Surg 2020;109:1646-55.

18. Speir AM, Kasirajan V, Barnett SD, et al. Additive costs of postoperative complications for isolated coronary artery 
bypass grafting patients in Virginia. Ann Thorac Surg 2009;88:40-5; discussion 5-6.

19. Landi H. Report: Federal Health IT Spending Will Increase to \$6.4 Billion in 2021. Hea!thcare Innovation. 2017. Available online: https://www.hcinnovationgroup. com/population-health-management/news/13027943/ report-federal-health-it-spending-will-increase-to-64billion-in-2021. Accessed July 82020.

20. Gondi S. The Burgeoning Role of Venture Capital in Health Care. Health Affairs. 2019. Available online: https://www.healthaffairs.org/do/10.1377/ hblog20181218.956406/full/. Accessed July 82020.

21. Digital Health. Available online: https://www.digital. health. Accessed July 82020.

22. Alliance of Advanced BioMedical Engineering. Internet of Medical Things Revolutionizing Healthcare. 2017. Available online: https://aabme.asme.org/posts/internetof-medical-things-revolutionizing-healthcare. Accessed July 82020.

23. U.S. Food \& Drug Administration. Digital Health. 2020. Available online: https://www.fda.gov/medical-devices/ digital-health. Accessed July 82020.

24. Feeley D. The Triple Aim or the Quadruple Aim? Four Points to Help Set Your Strategy. Institute for Healthcare Improvement. 2017. Available online: http://www.ihi.org/ communities/blogs/the-triple-aim-or-the-quadruple-aimfour-points-to-help-set-your-strategy. Accessed July 8 2020.

25. Baxter R, Squiers J, Conner W, et al. Enhanced Recovery After Surgery: A narrative review of its application in cardiac surgery. Ann Thorac Surg 2020;109:1937-44.

26. Engelman DT, Ben Ali W, Williams JB, et al. Guidelines for perioperative care in cardiac surgery: Enhanced Recovery After Surgery society recommendations. JAMA Surg 2019;154:755-66.

27. Kehlet H. Multimodal approach to control postoperative pathophysiology and rehabilitation. Br J Anaesth 1997;78:606-17.

28. Ljungqvist O, Scott M, Fearon KC. Enhanced Recovery After Surgery: A review. JAMA Surg 2017;152:292-8.

29. Carli F. Physiologic considerations of Enhanced Recovery After Surgery (ERAS) programs: implications of the stress response. Can J Anaesth 2015;62:110-9.

30. Laffey JG, Boylan JF, Cheng DC. The systemic inflammatory response to cardiac surgery: implications for the anesthesiologist. Anesthesiology 2002;97:215-52.

31. Chatterjee S. Commentary: Enhanced recovery after cardiac surgery: A game changer, passing fad, or somewhere in between? J Thorac Cardiovasc Surg 2019;157:1889-90.

32. Lai FY, Abbasciano RG, Tabberer B, et al. Identifying research priorities in cardiac surgery: a report from the James Lind Alliance Priority Setting Partnership in adult heart surgery. BMJ Open 2020;10:e038001.

33. Marzorati C, Pravettoni G. Value as the key concept in the health care system: how it has influenced medical practice and clinical decision-making processes. J Multidiscip Healthc 2017;10:101-6.

34. Malone TW. The Future of Work: How the New Order of Business Will Shape Your Organization, Your Management Style and Your Life. Harvard Business Review Press; 2004.

35. Rogers EM. Diffusion of Innovations. 5th ed. Free Press; 2003.

36. Diamandis PH, Kotler S. The Future is Faster Than You Think: How Converging Technologies Are Transforming Business, Industries, and Our Lives (Exponential Technology Series). Simon \& Schuster; 2020.

37. Lidl M, Robinson T, Moorhouse J. The next generation data platform. 2018. Available online: https://www2. deloitte.com/content/dam/Deloitte/lu/Documents/ technology/lu-next-generation-data-platform.pdf. Accessed July 82020.

38. Kraft D. 'Connected' and High-Tech: Your Medical Future. National Geographic: The Future of Medicine. 2019. Available online: https://static1.squarespace.com/ static/58a10123e58c624794f66f85/t/5cb9f3638165f5 c49f0b2fc9/1555690341229/National+Geographic+Future+of+Medicine.pdf. Accessed June 152020.

39. Harnessing the Power of Data in Health. Stanford Medicine. 2017. Available online: https://med.stanford. edu/content/dam/sm/sm-news/documents/StanfordMed icineHealthTrendsWhitePaper2017.pdf. Accessed July 8 2020.

40. Accenture. Artificial Intelligence Insights. 2020. Available online: https://www.accenture.com/us-en/insight-artificialintelligence-healthcare. Accessed July 82020.

41. Deloitte. Global Mobile Consumer Trends, 2nd Edition. Deloitte. 2017. Available online: https://www2.deloitte. com/content/dam/Deloitte/us/Documents/technologymedia-telecommunications/us-global-mobile-consumersurvey-second-edition.pdf. Accessed July 82020.

42. Deloitte. Global Mobile Consumer Trends 2017. Deloitte. 2017. Available online: https://www2.deloitte.com/il/ en/pages/technology-media-and-telecommunications/ articles/global-mobile-consumer-survey.html. Accessed July 82020 . 
43. Deloitte. 2018 Global Mobile Consumer Survey: US Edition. Deloitte. 2018. Available online: https://www2. deloitte.com/content/dam/Deloitte/us/Documents/ technology-media-telecommunications/us-tmt-globalmobile-consumer-survey-exec-summary-2018.pdf. Accessed July 82020.

44. Goldman Sachs. The Internet of Things: Making Sense of the Next Mega-Trend. 2014. Available online: https:// www.goldmansachs.com/insights/pages/internet-ofthings/iot-report.pdf. Accessed July 82020.

45. Evangelista L, Steinhubl SR, Topol EJ. Digital health care for older adults. Lancet 2019;393:1493.

46. Elliott T, Tong I, Sheridan A, et al. Beyond convenience: Patients' perceptions of physician interactional skills and compassion via telemedicine. Mayo Clin Proc Innov Qual Outcomes 2020;4:305-14.

47. Charness N, Fox M, Papadopoulos A, et al. Metrics for assessing the reliability of a telemedicine remote monitoring system. Telemed J E Health 2013;19:487-92.

48. Evans J, Papadopoulos A, Silvers CT, et al. Remote health monitoring for older adults and those with heart failure: Adherence and system usability. Telemed J E Health 2016;22:480-8.

49. Krishnaswami A, Beavers C, Dorsch MP, et al. Gerotechnology for older adults with cardiovascular diseases: JACC state-of-the-art review. J Am Coll Cardiol 2020;76:2650-70.

50. Turakhia MP, Shafrin J, Bognar K, et al. Estimated prevalence of undiagnosed atrial fibrillation in the United States. PLoS One 2018;13:e0195088.

51. Perez MV, Mahaffey KW, Hedlin H, et al. Large-scale assessment of a smartwatch to identify atrial fibrillation. $\mathrm{N}$ Engl J Med 2019;381:1909-17.

52. Turakhia MP, Desai M, Hedlin H, et al. Rationale and design of a large-scale, app-based study to identify cardiac arrhythmias using a smartwatch: The Apple Heart Study. Am Heart J 2019;207:66-75.

53. U.S. National Library of Medicine. Apple Heart Study: Assessment of Wristwatch-Based Photoplethysmography to Identify Cardiac Arrhythmias. 2017. Available online: https:/clinicaltrials.gov/ct2/show/NCT03335800. Accessed July 82020.

54. Turing AM. Computing machinery and intelligence. Mind 1950;LIX:433-60.

55. The Lancet. Artificial intelligence in health care: within touching distance. Lancet 2018;390:2739.

56. Merriam-Webster. Artificial Intelligence. Available online: https://www.merriam-webster.com/dictionary/ artificial\%20intelligence. Accessed July 82020.

57. van Duin S, Bakhshi N. Part 1: Artificial Intelligence Defined. Deloitte. 2017. Available online: https://www2. deloitte.com/se/sv/pages/technology/articles/part1artificial-intelligence-defined.html. Accessed July 82020.

58. Baxter RD, Fann JI, DiMaio JM, et al. Digital health primer for cardiothoracic surgeons. Ann Thorac Surg 2020.

59. Kilic A. Artificial intelligence and machine learning in cardiovascular health care. Ann Thorac Surg 2020;109:1323-9.

60. Frost \& Sullivan. From $\$ 600 M$ to $\$ 6$ Billion, Artificial Intelligence Systems Poised for Dramatic Market Expansion in Healthcare. 2016. Available online: https:// ww2.frost.com/news/press-releases/600-m-6-billionartificial-intelligence-systems-poised-dramatic-marketexpansion-healthcare/. Accessed July 82020.

61. Markets and Markets. Artificial Intelligence in Healthcare Market with Covid-19 Impact Analysis by Offering (Hardware, Software, Services), Technology (Machine Learning, NLP, Context-Aware Computing, Computer Vision), End-Use Application, End User and Region Global Forecast to 2026. 2020. Available online: https:// www.marketsandmarkets.com/Market-Reports/artificialintelligence-healthcare-market-54679303.html. Accessed July 82020 .

62. Accenture. Artificial Intelligence (AI): Healthcare's New Nervous System. 2020. Available online: https://www. accenture.com/us-en/insight-artificial-intelligencehealthcare\%C2\%A0. Accessed July 82020.

63. Norrie J. The challenge of implementing AI models in the ICU. Lancet Respir Med 2018;6:886-8.

64. U.S. Food \& Drug Administration. Proposed Regulatory Framework for Modifications to Artificial Intelligence/ Machine Learning (AI/ML)-Based Software as a Medical Device. Available online: https://www.fda.gov/ media/122535/download. Accessed July 82020.

65. Lobdell KW, Fann JI, Sanchez JA. "What's the risk?" Assessing and mitigating risk in cardiothoracic surgery. Ann Thorac Surg 2016;102:1052-8.

66. Mullainathan S, Obermeyer Z. Does machine learning automate moral hazard and error? Am Econ Rev 2017;107:476-80.

67. Johnson KW, Torres Soto J, Glicksberg BS, et al. Artificial intelligence in cardiology. J Am Coll Cardiol 2018;71:2668-79.

68. Lopez-Jimenez F, Attia Z, Arruda-Olson AM, et al. Artificial intelligence in cardiology: Present and future. 
Mayo Clin Proc 2020;95:1015-39.

69. Yan Y, Zhang JW, Zang GY, et al. The primary use of artificial intelligence in cardiovascular diseases: what kind of potential role does artificial intelligence play in future medicine? J Geriatr Cardiol 2019;16:585-91.

70. U.S. Department of Health \& Human Services. Computational Modeling. 2020. Available online: https:// www.nibib.nih.gov/science-education/science-topics/ computational-modeling. Accessed July 82020.

71. Lee LC, Genet M, Dang AB, et al. Applications of computational modeling in cardiac surgery. J Card Surg 2014;29:293-302.

72. Sun K, Zhang Z, Suzuki T, et al. Dor procedure for dyskinetic anteroapical myocardial infarction fails to improve contractility in the border zone. J Thorac Cardiovasc Surg 2010;140:233-9, 9 e1-4.

73. Wenk JF, Ge L, Zhang Z, et al. Biventricular finite element modeling of the Acorn CorCap Cardiac Support Device on a failing heart. Ann Thorac Surg 2013;95:2022-7.

74. Catalia Health. The Catalia Health Platform: How It Works. 2020. Available online: http://www.cataliahealth. com/how-it-works/. Accessed July 82020.

75. Deloitte. The Future of Virtual Health. Deloitte. 2020. Available online: https://www2.deloitte.com/us/en/ insights/industry/health-care/future-of-virtual-health. html. Accessed July 82020.

76. GE Additive. What Is Additive Manufacturing? General Electric. 2020. Available online: https://www.ge.com/ additive/additive-manufacturing. Accessed July 82020.

77. 3D Systems. Our Story. 2020. https://www.3 dsystems. com/our-story. Accessed July 82020.

78. Vukicevic M, Mosadegh B, Min JK, et al. Cardiac 3D printing and its future directions. JACC Cardiovasc Imaging 2017;10:171-84.

79. Porsche Cars North America Inc. Porsche "Tech Live Look" Pioneers Augmented Reality in U.S. Auto Repairs. PR Newswire. 2018. Available online: https:// www.prnewswire.com/news-releases/porsche-techlive-look-pioneers-augmented-reality-in-us-autorepairs-300655775.html. Accessed July 82020.

80. Cleveland Clinic. Virtual Reality: Can It Train You to Do Heart Surgery? Cleveland Clinic. 2018. Available online: https://health.clevelandclinic.org/how-virtual-reality-cantrain-a-future-heart-surgeon/. Accessed July 82020.

81. Friedl R, Preisack MB, Klas W, et al. Virtual reality and $3 \mathrm{D}$ visualizations in heart surgery education. Heart Surg Forum 2002;5:E17-21.

82. Zhao D, Ma L, Ma C, et al. Floating autostereoscopic
3D display with multidimensional images for telesurgical visualization. Int J Comput Assist Radiol Surg 2016;11:207-15.

83. Currie ME, McLeod AJ, Moore JT, et al. Augmented reality system for ultrasound guidance of transcatheter aortic valve implantation. Innovations (Phila) 2016;11:319; discussion 39.

84. Grant EK, Olivieri LJ. The role of 3-D heart models in planning and executing interventional procedures. Can J Cardiol 2017;33:1074-81.

85. Cooper S, Buykx P, McConnell-Henry T, et al. Simulation: can it eliminate failure to rescue? Nurs Times 2011;107:18-20.

86. Edwards FH, Ferraris VA, Kurlansky PA, et al. Failure to rescue rates after coronary artery bypass grafting: An analysis from the Society of Thoracic Surgeons Adult Cardiac Surgery Database. Ann Thorac Surg 2016;102:458-64.

87. Breslow MJ, Rosenfeld BA, Doerfler M, et al. Effect of a multiple-site intensive care unit telemedicine program on clinical and economic outcomes: an alternative paradigm for intensivist staffing. Crit Care Med 2004;32:31-8.

88. Celi LA, Hassan E, Marquardt C, et al. The eICU: it's not just telemedicine. Crit Care Med 2001;29:N183-9.

89. Lilly CM, McLaughlin JM, Zhao H, et al. A multicenter study of ICU telemedicine reengineering of adult critical care. Chest 2014;145:500-7.

90. Lilly CM, Mickelson JT. Evolution of the intensive care unit telemedicine value proposition. Crit Care Clin 2019;35:463-77.

91. Lilly CM, Motzkus C, Rincon T, et al. ICU telemedicine program financial outcomes. Chest 2017;151:286-97.

92. Willmitch B, Golembeski S, Kim SS, et al. Clinical outcomes after telemedicine intensive care unit implementation. Crit Care Med 2012;40:450-4.

93. Bender W, Hiddleson CA, Buchman TG. Intensive care unit telemedicine: Innovations and limitations. Crit Care Clin 2019;35:497-509.

94. Meyer A, Zverinski D, Pfahringer B, et al. Machine learning for real-time prediction of complications in critical care: a retrospective study. Lancet Respir Med 2018;6:905-14.

95. Vranas KC, Jopling JK, Sweeney TE, et al. Identifying distinct subgroups of ICU patients: A machine learning approach. Crit Care Med 2017;45:1607-15.

96. Lobdell K. Innovative methods to transform cardiac care have never been better. 2019. Available online: https:// opmed.doximity.com/articles/innovative-methods-to- 
transform-cardiac-care-have-never-been-better?_csrf_ attempted=yes. Accessed August 52020.

97. Lobdell K, Linblom S. Tele-ICU: Transforming Cardiac Critical Care Quality \& Value. 52nd Annual Society of Thoracic Surgeons Meeting; Jan 23-27; Phoenix, Arizona2016.

98. Gregory AJ, Grant MC, Boyle E, et al. Cardiac surgeryenhanced recovery programs modified for COVID-19: Key steps to preserve resources, manage caseload backlog, and improve patient outcomes. J Cardiothorac Vasc Anesth 2020;34:3218-24.

99. Baker S. Health Care Data Hacks Are on the Rise. Axios. 2018. Available online: https://www.axios.com/healthcare-data-privacy-hacking-9fff9d57-789b-481c-a4bb03609f2307c5.html. Accessed July 82020.

100. Chernyshev M, Zeadally S, Baig Z. Healthcare data breaches: Implications for digital forensic readiness. J Med Syst 2018;43:7.

101.Hsu J. The Strava Heat Map and the End of Secrets. Wired. 2018. Available online: https://www.wired.com/ story/strava-heat-map-military-bases-fitness-trackersprivacy/. Accessed July 82020.

102.U.S. Food \& Drug Administration. Firmware Update to Address Cybersecurity Vulnerabilities Identified in Abbott's (formerly St. Jude Medical's) Implantable Cardiac Pacemakers: FDA Safety Communication. 2017. Available online: https://www.fda.gov/medical-devices/safetycommunications/firmware-update-address-cybersecurityvulnerabilities-identified-abbotts-formerly-st-judemedicals. Accessed July 82020.

103.Lobdell K, Hariharan S, Smith W, et al. Improving Health Care Leadership in the COVID-19 Era. NEJM Catalyst. 2020. Available online: https://catalyst.nejm.org/doi/ full/10.1056/CAT.20.0225. Accessed July 82020.

104. Rose G. Tapping Telemedicine for Cardiac Patients During the COVID-19 Pandemic. U.S. News. 2020. Available online: https://www.usnews.com/news/ healthiest-communities/articles/2020-04-13/tappingtelemedicine-for-cardiac-patients-during-the-coronaviruspandemic. Accessed July 82020.

105. Bestsennyy O, Gilbert G, Harris A, et al. Telehealth: A Quarter-Trillion-Dollar Post-COVID-19 Reality? McKinsey \& Company. 2020. Available online: https:// www.mckinsey.com/industries/healthcare-systems-andservices/our-insights/telehealth-a-quarter-trillion-dollarpost-covid-19-reality\#. Accessed July 82020.

106. Carium. Home page. Carium. 2020. Available online: www.carium.com. Accessed July 82020.
107.SeamlessMD. Home page. SeamlessMD. 2020. Available online: https://seamless.md/. Accessed July 82020.

108. Mehaffey JH, Hawkins RB, Byler M, et al. Cost of individual complications following coronary artery bypass grafting. J Thorac Cardiovasc Surg 2018;155:875-82 e1.

109. Osnabrugge RL, Speir AM, Head SJ, et al. Costs for surgical aortic valve replacement according to preoperative risk categories. Ann Thorac Surg 2013;96:500-6.

110. Duke University School of Medicine. Home page. Duke University School of Medicine. 2020. Available online: https://anesthesiology.duke.edu/?page_id=853947\#t ab-1573746742533-4-8. Accessed July 92020.

111.Perioperative Exercise Testing \& Training Society. Home page. Perioperative Exercise Testing \& Training Society. Available online: https://www.poetts.co.uk/. Accessed July 82020.

112. Society for Perioperative Assessment and Quality Improvement. Home page. Society for Perioperative Assessment and Quality Improvement. 2019. Available online: https://www.spaqi.org/2020/. Accessed July 82020.

113.Everett AD, Alam SS, Owens SL, et al. The association between cytokines and 365-day readmission or mortality in adult cardiac surgery. J Extra Corpor Technol 2019;51:201-9.

114.Jacobs JP, Alam SS, Owens SL, et al. The association between novel biomarkers and 1-year readmission or mortality after cardiac surgery. Ann Thorac Surg 2018;106:1122-8.

115.Lobdell KW, Parker DM, Likosky DS, et al. Preoperative serum ST2 level predicts acute kidney injury after adult cardiac surgery. J Thorac Cardiovasc Surg 2018;156:1114$23 \mathrm{e} 2$.

116. Goel NJ, Iyengar A, Kelly JJ, et al. Volume of frail patients predicts outcome in frail patients after cardiac surgery. J Thorac Cardiovasc Surg 2020.

117.Sepehri A, Beggs T, Hassan A, et al. The impact of frailty on outcomes after cardiac surgery: a systematic review. J Thorac Cardiovasc Surg 2014;148:3110-7.

118. Allyn J, Allou N, Augustin P, et al. A comparison of a machine learning model with EuroSCORE II in predicting mortality after elective cardiac surgery: A decision curve analysis. PLoS One 2017;12:e0169772.

119.Lee HC, Yoon HK, Nam K, et al. Derivation and validation of machine learning approaches to predict acute kidney injury after cardiac surgery. J Clin Med 2018;7:322.

120. Siregar S, Nieboer D, Vergouwe Y, et al. Improved prediction by dynamic modeling: An exploratory study in the adult cardiac surgery database of the Netherlands 
Association for Cardio-Thoracic Surgery. Circ Cardiovasc Qual Outcomes 2016;9:171-81.

121.Al'Aref SJ, Anchouche K, Singh G, et al. Clinical applications of machine learning in cardiovascular disease and its relevance to cardiac imaging. Eur Heart J 2019;40:1975-86.

122. Retson TA, Besser AH, Sall S, et al. Machine learning and deep neural networks in thoracic and cardiovascular imaging. J Thorac Imaging 2019;34:192-201.

123.Topol EJ. High-performance medicine: the convergence of human and artificial intelligence. Nat Med 2019;25:44-56.

124. Alsharqi M, Woodward WJ, Mumith JA, et al. Artificial intelligence and echocardiography. Echo Res Pract 2018;5:R115-25.

125. Arafati A, Hu P, Finn JP, et al. Artificial intelligence in pediatric and adult congenital cardiac MRI: an unmet clinical need. Cardiovasc Diagn Ther 2019;9:S310-25.

126. Topol E, Lee KF. It takes a planet. Nat Biotechnol 2019;37:858-61.

127. Coala. Home page. Coala. Available online: https://www. coalalife.com/us/science/. Accessed July 92020.

128. Endotronix. Home page. Endotronix. 2020. Available online: https://endotronix.com. Accessed July 92020.

129. Cloud DX. Remote Patient Monitoring. Cloud DX. 2020. Available online: https://clouddx.com/\#/ remotepatientmonitoring. Accessed July 92020.

130. Current Health. Product. Current Health. 2020. Available online: https://currenthealth.com/product. Accessed July 9 2020.

131. Graftworx. Products. Graftworx. Available online: https:// www.graftworx.com/products. Accessed July 92020.

132.Statis Labs Inc. Home page. Stasis Labs Inc. 2019. Available online: https://www.stasislabs.com. Accessed July 92020.

133. VitalConnect. Home page. VitalConnect. 2019. Available online: https://vitalconnect.com. Accessed July 92020.

134. Vivalnk. Continuous non-invasive blood pressure (CNIBP) and vital signs monitoring. Vivalnk. Available online: http://www.vivalnk.com/solutions/continuous-vital-signsmonitoring. Accessed July 92020.

135. Choi PJ, Oskouian RJ, Tubbs RS. Telesurgery: Past, present, and future. Cureus 2018;10:e2716.

136. Meltzer AJ, Hallbeck MS, Morrow MM, et al. Measuring ergonomic risk in operating surgeons by using wearable technology. JAMA Surgery 2020;155:444-6.

137. O'Sullivan S, Nevejans N, Allen C, et al. Legal, regulatory, and ethical frameworks for development of standards in artificial intelligence (AI) and autonomous robotic surgery. Int J Med Robot 2019;15:e1968.

138. Bodenstedt S, Rivoir D, Jenke A, et al. Active learning using deep Bayesian networks for surgical workflow analysis. Int J Comput Assist Radiol Surg 2019;14:1079-87.

139. Gawande A. Personal Best. Conde Nast. 2020.

Available online: https://www.newyorker.com/

magazine/2011/10/03/personal-best. Accessed July 92020.

140. Arena Labs. The Future of Medical Learning. YouTube. 2020. Available online: https://youtu.be/PocgKS9qmbg. Accessed July 92020.

141. Arena Labs. Performance Under Stress. Arena Labs. 2020. Available online: https://arenalabs.global/performanceunder-stress/. Accessed July 92020.

142. Surgical Safety Technologies. Home page. Surgical Safety Technologies. 2020. Available online: https://www. surgicalsafety.com/. Accessed July 92020.

143. Goldenberg MG, Jung J, Grantcharov TP. Using data to enhance performance and improve quality and safety in surgery. JAMA Surg 2017;152:972-3.

144.Jung JJ, Juni P, Lebovic G, et al. First-year analysis of the operating room black box study. Ann Surg 2020;271:122-7.

145. Kolodzey L, Trbovich P, Kashfi A, et al. System factors affecting intraoperative risk and resilience: Applying a novel integrated approach to study surgical performance and patient safety. Ann Surg 2020;272:1164-70.

146. Haldor Advanced Technologies. Home page. Haldor Advanced Technologies. Available online: https://www. haldor-tech.com/. Accessed July 92020.

147.Lazzaro A, Corona A, Iezzi L, et al. Radiofrequency-based identification medical device: An evaluable solution for surgical sponge retrieval? Surg Innov 2017;24:268-75.

148. Wyss Institute for Biologically Inspiring Engineering. Smart Tools: RFID Tracking for Surgical Instruments. Wyss Institute. 2020. Available online: https://wyss. harvard.edu/technology/smart-tools-rfid-tracking-forsurgical-instruments/ Accessed July 92020.

149.Landro L. Hospital ICUs Mine Big Data in Push for Better Outcomes. The Wall Street Journal. 2015. Available online: https://www.wsj.com/articles/hospital-icus-minebig-data-in-push-for-better-outcomes-1435249003. Accessed July 92020.

150.Perfect Care. Patients. Perfect Care. Available online: https://perfectcare.org/patients-2/. Accessed July 92020.

151.Atrium Health. Innovative Solutions Are Helping Bridge North Carolina's Rural Healthcare Gap. Atrium Health. 2019. Available online: https://atriumhealth.org/ 
dailydose/2018/09/06/innovative-solutions-are-helpingbridge-north-carolinas-rural-healthcare-gap. Accessed July 92020.

152.Sands A. Atrium Health Pilot Could Help Narrow Rural Health-Care Gap Through Emerging Tech. American City Business Journal. 2018. Available online: https:// www.bizjournals.com/charlotte/news/2018/07/10/atriumhealth-pilot-could-help-narrow-rural-health.html. Accessed July 92020.

153.Kaiser Permanente. Cardiac Rehabilitation: Outpatient Program. Kaiser Foundation Health Plan, Inc. 2020. Available online: https://healthy.kaiserpermanente.

doi: $10.21037 /$ jhmhp-20-114

Cite this article as: Lobdell KW, Appoo JJ, Rose GA, Ferguson B, Chatterjee S. Technological advances to enhance recovery after cardiac surgery. J Hosp Manag Health Policy 2021;5:30. org/health-wellness/health-encyclopedia/he.cardiacrehabilitation-outpatient-program.hw230413. Accessed July 92020.

154.Lear SA, Singer J, Banner-Lukaris D, et al. Randomized trial of a virtual cardiac rehabilitation program delivered at a distance via the Internet. Circ Cardiovasc Qual Outcomes 2014;7:952-9.

155. Shah A. Kaiser Permanente Bets on Smartwatches to Lower Costs. The Wall Street Journal. 2020. Available online: https://www.wsj.com/articles/kaiser-permanentebets-on-smartwatches-to-lower-costs-11578565801. Accessed July 92020. 